\title{
PREPARING CHITOSAN FROM SHRIMP SKIN AND OPERATING IT WITH EDTA AND USED IN THE REMOVAL OF HEAVY METALS OF WATER
}

\author{
Shahla Mozaffari ${ }^{1 *}$, Narges Ajami ${ }^{1}$, Juliet Ordoukhanin ${ }^{1}$, Khadijeh Abdollahi ${ }^{1}$

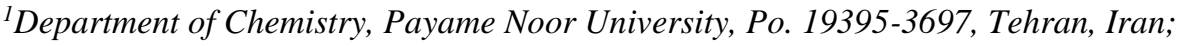

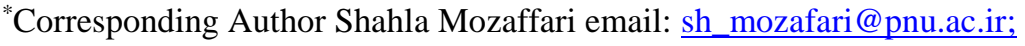

"Received March 2019; Accepted April 2019; Published June 2019;

DOI: https://doi.org/10.31407/ijees9219

UOI license: http://u-o-i.org/1.01/ijees/94657212

\begin{abstract}
The use of bio-polymers due to bio-degradability and low cost has been considered for the removal of heavy metals from water and wastewater. Chitosan polymer is a hydrophilic Cation that removes acetyl ketamine from the alkaline environment and is widely used as a sorbent for the removal of heavy metals. Chitosan is a biopolymer that has been widely used in a variety of fields, such as bio-medicine, water purification and food industries, due to its low prices and biological properties, such as biodegradability, antibacterial and harmlessness. After preparation, it was measured by atomic absorption and FT-IR methods. The impact of various parameters such as: $\mathrm{pH}$, metal ion density, amount of adsorbent and the duration of mixing was studied to provide stable and optimal conditions for determining the selectivity of removing heavy metals from copper and nickel. The absorption isotherm was studied by Langmuir and Freundlich models. The results show that the adsorption rate with chitosan agent is optimized at $\mathrm{pH}=5$, the time of 30 minutes and the amount of adsorbent $120 \mathrm{mg}$ and the concentration of ion $4 \mathrm{mg}$ with an absorption of $99 \%$ and the amount of adsorption with operating chitosan in optimized conditions at $\mathrm{pH}=9$, the duration of 5 minutes and the absorbance of $100 \mathrm{mg}$ and the concentration of ion $2 \mathrm{mg}$ with absorption is $93.8 \%$.
\end{abstract}

Key words: Chitosan, shrimp skin, operating with EDTA, Heavy metals 